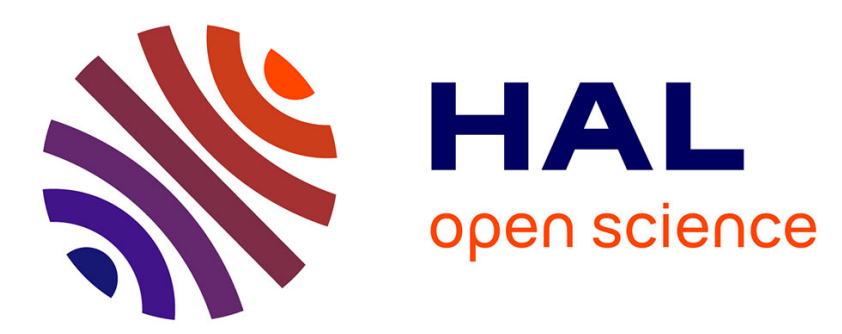

\title{
The flow in an oil/water plate heat exchanger for the automotive industry
}

\author{
A. Lozano, F. Barreras, N. Fueyo, S. Santodomingo
}

\section{To cite this version:}

A. Lozano, F. Barreras, N. Fueyo, S. Santodomingo. The flow in an oil/water plate heat exchanger for the automotive industry. Applied Thermal Engineering, 2008, 28 (10), pp.1109. 10.1016/j.applthermaleng.2007.08.015 . hal-00498962

\section{HAL Id: hal-00498962 \\ https://hal.science/hal-00498962}

Submitted on 9 Jul 2010

HAL is a multi-disciplinary open access archive for the deposit and dissemination of scientific research documents, whether they are published or not. The documents may come from teaching and research institutions in France or abroad, or from public or private research centers.
L'archive ouverte pluridisciplinaire HAL, est destinée au dépôt et à la diffusion de documents scientifiques de niveau recherche, publiés ou non, émanant des établissements d'enseignement et de recherche français ou étrangers, des laboratoires publics ou privés. 


\section{Accepted Manuscript}

The flow in an oil/water plate heat exchanger for the automotive industry

\section{APPLIED}

\section{THERMAL}

ENGINEERING

A. Lozano, F. Barreras, N. Fueyo, S. Santodomingo

PII:

S1359-4311(07)00294-3

DOI:

10.1016/j.applthermaleng.2007.08.015

Reference:

ATE 2257

To appear in:

Applied Thermal Engineering

Received Date: $\quad 4$ January 2007

Revised Date: $\quad 24$ August 2007

Accepted Date: $\quad 31$ August 2007

Please cite this article as: A. Lozano, F. Barreras, N. Fueyo, S. Santodomingo, The flow in an oil/water plate heat exchanger for the automotive industry, Applied Thermal Engineering (2007), doi: 10.1016/j.applthermaleng. 2007.08.015

This is a PDF file of an unedited manuscript that has been accepted for publication. As a service to our customers we are providing this early version of the manuscript. The manuscript will undergo copyediting, typesetting, and review of the resulting proof before it is published in its final form. Please note that during the production process errors may be discovered which could affect the content, and all legal disclaimers that apply to the journal pertain. 


\title{
THE FLOW IN AN OIL/WATER PLATE HEAT EXCHANGER FOR THE AUTOMOTIVE INDUSTRY
}

\author{
A. Lozano* ${ }^{1}$, F. Barreras*, N. Fueyo ${ }^{\dagger}$, S. Santodomingo ${ }^{*}$ \\ * LITEC/CSIC, María de Luna 10, 50018, Zaragoza, Spain \\ ${ }^{\dagger}$ LITEC/Universidad de Zaragoza, María de Luna 3, 50018, Zaragoza, Spain \\ ${ }^{\ddagger}$ Valeo Engine Cooling - Spain Division, ctra. Logroño km. 8.9, 50011 Zaragoza, Spain
}

\begin{abstract}
This paper presents an experimental and numerical work to analyze the flow in an oil/water plate heat exchanger for the automotive industry. The plate heat exchanger is designed as twenty-one equal plates assembled in a stack. Each plate has a series of grooves in the surface, and is mounted upside down with respect to the preceding one, so that channels are formed that should direct the fluid motion and increase the heat transfer area. The flow has been experimentally studied by means of planar laser-induced fluorescence (PLIF) to visualize its structure, and particle image velocimetry (PIV) with fluorescent particle tracers to measure its velocity. It has also been numerically simulated. In both cases, it has been observed that, for the analyzed design and either for oil or water, the flow is not uniform, and preferentially moves along the lateral extremes of the plates that conform the heat exchanger.
\end{abstract}

\section{Key words:}

plate heat exchangers, herringbone heat exchangers, flow visualization, flow numerical simulation

\footnotetext{
${ }^{1}$ Corresponding author: alozano@litec.csic.es Tel: 34976716463 Fax: 34976716456
} 


\section{INTRODUCTION}

The increasingly restrictive laws regulating pollutant emissions from all kinds of automobiles, together with the continuous rising in the gasoline and diesel price justify the enormous research effort devoted to optimizing the efficiency of IC engines, and to reduce their maintenance costs. As an improving element, it has been suggested to include an oil/water heat exchanger to cool down the lubricating oil, preventing its degradation, extending its useful life, and enhancing the engine lubrication. As cooling fluid, the water from the car cooling circuit would be used. To be able to conveniently fit the exchanger near the car engine, it should be small and, preferably, light. Furthermore, to minimize costs, this unit should be simple and inexpensive. To fulfill all these requirements, serpentine, laminated, and parallel flow heat exchangers have been developed as an alternative to traditional fin-tube types.

An interesting possibility is to use a plate heat exchanger. This type of exchangers, introduced by Richard Seligman in 1923, consists of a series of thin corrugated metal plates that are piled up and clamped together, separated by sealing gaskets, so that the corrugations in adjacent plates form a series of channels, where the heat-exchanging fluids circulate [1]. Although these devices where first devised for the dairy industry, they are becoming increasingly popular and now they are common in many chemical and process industries. Among other advantages, they are compact, easily manufactured, simple to maintain and clean, and have very high heat exchange coefficients, enhanced by the often turbulent flow [2]. They can have 50\% less volume than a fined tube heat exchanger, and $60 \%$ less than a serpentine one for the same thermal performance. The plate corrugations contribute to increase the total interchange surface and the flow path, consequently increasing the fluid residence time. In this way, a heat transfer coefficient 3 to 4 times higher than that for smooth channels can be achieved [3]. The effect on the heat transfer coefficient is similar to that produced by helical micro fin tubes when compared to smooth ones [4]. However, although several recent studies have discussed the thermal aspects of plate heat exchangers $[5,6]$, details of the internal flow distribution are, in most cases, still unknown. 
For this reason, this paper presents a study of the flow in a grooved plate heat exchanger with a herringbone configuration. The device here analyzed is a first prototype aimed for commercial purposes in the automotive industry, and the objective of the study is to evaluate its performance in order to improve it, and hence, the competitiveness of the system. Planar laser-induced fluorescence has been applied to visualize the streamlines, while particle image velocimetry has been employed to measure the velocity filed inside the plates. Simultaneously, the flow has also been numerically simulated using the CFD FLUENT code. An excellent agreement between experimental and numerical results have been obtained revealing interesting details of the flowfield.

\section{DESCRIPTION OF THE EXPERIMENTS}

The plate heat exchanger here studied is designed as a series of twenty-one equal plates that are stacked forming a pile, so that each plate is mounted upside down with respect to the preceding one (i.e. after an in-plane $180^{\circ}$ rotation). The plates, made of aluminum, are small trays $6 \mathrm{~cm} \times 9.5 \mathrm{~cm}$ with a depth of $0.5 \mathrm{~cm}$. In its surface, there is a series of V-shaped grooves $0.9 \mathrm{~mm}$ deep, with a semi-circular cross-section, in a herringbone pattern (see, for example, [3,7]). When assembled, the corrugations of both plates form a series of channels that are expected to force the fluid to flow in a zigzag trajectory in order to increase the heat transfer area. The fluids, oil or water, circulate in the gaps between two contiguous plates, in alternate layers. Each plate has four orifices, two at each end. When a pair of plates is stacked together, two orifices serve as flow inlet and outlet, while the other two form a passing cylinder, so that the fluid is conducted to the adjacent plates. Figure 1 a) shows one of the plates, while Fig. 1 b) is a sketch of the stacking arrangement.

The system is designed for water flow rates ranging from 13 to 20 1/min, and oil flow rates from 5 to $301 / \mathrm{min}$.

It might be relevant to indicate that although stainless steel is generally preferred in most exchangers designed for process industries, mainly due to corrosion, cleanliness or mechanical requirements, aluminum is the material of choice for most of the automotive 
heat exchangers. Almost $100 \%$ of the oil coolers such as the one presented in this study are made of aluminum because of its good thermal properties and low weight. For serial manufacturing, the aluminum plates are brazed together in a controlled atmosphere furnace to produce a completely sealed heat exchanger in one shot, which is very convenient for the mass volume productions of the automotive industry.

As representative of the whole heat exchanger, the flow between two plates has been analyzed, by planar laser-induced fluorescence visualization (PLIF) and particle image velocimetry (PIV). As both techniques require optical access, one of the plates has been an original unmodified one, supported by a $13,5 \times 10,3 \times 7,5 \mathrm{~cm}$ aluminum block. The other has been replaced by a transparent metacrylate piece, machined with the same embossed inner surface as the plates, but flat on the outer side, that was bolted to the aluminum block, sealing the joint with a rubber gasket. After machining, the piece had to be polished to achieve the transparency requirements needed to apply the experimental techniques. The assembly is shown in Fig. 2. The plate has been painted in black to minimize stray reflections. The setup is completed with a liquid tank, a $200 \mathrm{~W}$ pump capable of delivering a maximum flow rate of $100 \mathrm{l} / \mathrm{h}$ with a pressure head of $7 \mathrm{~m}$, a regulation valve and a rotameter.

The working fluids have been water, and, replacing the motor oil, a mixture of $55 \%$ water and $45 \%$ glycerin adjusted to have the same kinematic viscosity of the oil, $6.5 \mathrm{cSt}$. This replacement, that obviously maintains dynamic similarity, poses several advantages. The viscosity can be varied by modifiying the glycerin percentage, and the mixture is colorless, cleaner and is not naturally fluorescent as opposed to most oils, which becomes an inconvenience when a luminescent tracer is to be tracked. The resultant flow should be essentially identical as that for oil, because it is controlled by the Reynolds number that is the same for both fluids. Effects due to non-equal parameters such as surface tension have to be negligible, as they are not included in the governing equations.

To illuminate the flow, a double cavity Quantel YG781C-10 pulsed Nd:YAG laser has been used, doubling the frequency of its emission to obtain $100 \mathrm{~mJ}$ pulses at $532 \mathrm{~nm}$, with a pulse duration of $6 \mathrm{~ns}$. In most PLIF and PIV experiments, the flow is sliced by a 
thin light sheet while the images are recorded at $90^{\circ}$ to avoid geometric distortions. In this case it was not possible to illuminate the flow from the side. Hence, the laser beam has been expanded into a slightly divergent cylinder of light that impinged on the exchanger surface at a $60^{\circ}$ angle, using a $-25 \mathrm{~mm}$ f.l. spherical lens placed at $1 \mathrm{~m}$ of the heat exchanger assembly. The recording cameras have been located perpendicular to the flow. This arrangement (Fig. 3) does not introduce any perspective distortion in the images and eliminates any possible direct reflection of the laser light on the CCD arrays.

To visualize the flow pattern, Sulforhodamine B (Kiton Red) dissolved either in water or in the water/glycerin mixture has been selected as the luminescent tracer. The absorption spectrum of Sulforhodamine B has a maximum at $556 \mathrm{~nm}$, hence excitation at $532 \mathrm{~nm}$ is very efficient [8]. The fluorescence peak of this dye is located at $620 \mathrm{~nm}$, which allows for an efficient discrimination between the emitted signal and the excitation laser light beam. To further decrease the background light, a Schott OG 550 filter has been placed in front of the camera lenses, blocking any residual $532 \mathrm{~nm}$ wavelength from the incident laser beam. The tracer has been injected in the heat exchanger plate inlet by means of a capillary tube with a diameter of $0.5 \mathrm{~mm}$. To vary the injection point, the tube could be displaced across the inlet section.

To obtain the PIV image pairs, the flow has to be seeded with particles to scatter a fraction of the incoming light. Preliminary tests were performed with standard PVC particles, aluminum oxide platelets and glass spheres. However, as side illumination was not possible in this specific experimental set up, the contrast between the light scattered by the particles and reflections in the test rig was insufficient, even though the back plate was painted in flat black to improve it. To circumvent this inconvenient, fluorescent particles have been used. The particles were manufactured in the laboratory, by grinding a block of epoxy resin in which Sulforhodamine B had been dissolved before curing. To add the dye, Sulforhodamine solid powder was previously dissolved in ethanol. Although Sulforhodamine is soluble in water, adding water to the resin prevented it from solidifying appropriately. The powder obtained from the grinding process had to be sieved and classified afterwards into different groups depending of the particle sizes. It was 
experimentally verified that fluorescent particles with a diameter around $50 \mu \mathrm{m}$ produced a satisfactory light emission, and also followed the small liquid flow structures.

Two CCD cameras have been used as imaging devices. In the visualization experiments, a $6 \times 8 \mathrm{~cm}$ field of view has been registered with a Princeton Instruments slow scan camera, with a $50 \mathrm{~mm} f \# 1.2$ Nikon lens with an approximate resolution of 200 $\mu \mathrm{m} /$ pixel. For the PIV measurements, a PivCam 10-30 camera with an interlined $9 \mu \mathrm{m}$ 1024 x 1024 Kodak CCD has been employed with a f\#2.8, $60 \mathrm{~mm}$ macro Nikon lens, covering a $3.2 \times 3.2 \mathrm{~cm}$ field of view with a resolution of $30 \mu \mathrm{m} /$ pixel. The time interval between paired images has varied between $150 \mu \mathrm{s}$ and $1 \mathrm{~ms}$.

The flow conditions that have been tested are water flow rates of $1.31 / \mathrm{min}$ and 2.0 $1 / \mathrm{min}$ and water/glycerin flow rates of $0.5,1.0,2.0$ and $3.01 / \mathrm{min}$. This flow rates are one tenth of the total flow rate that would circulate through the complete heat exchanger consisting of twenty-one plates.

\section{DESCRIPTION OF THE NUMERICAL PROCEDURE}

In addition to the experimental work detailed above, the device has been modeled with Computational Fluid Dynamics techniques using the CFD FLUENT code. As for the experimental work, the model comprises the channel between two neighboring exchanger plates. A mesh of tetrahedral cells has been used, totaling about 534,000 cells. Grid studies conducted with finer meshes (up to 740,000 cells) indicated that the results are gridindependent for this level of meshing. Figure 4 presents a detail of the computational domain, corresponding to the mesh on a fragment of the surface of one of the plates. The holes in the mesh correspond to contact points between the plate grooves, where soldering takes place during assembling.

Both water and oil flows have been analyzed, with water flow rates (per channel) ranging from $1.11 \mathrm{l} / \mathrm{min}$ to $2.08 \mathrm{l} / \mathrm{min}$ and oil ones from $0.45 \mathrm{l} / \mathrm{min}$ to $2.73 \mathrm{l} / \mathrm{min}$. The corresponding Reynolds numbers, based on the average velocity in the cross-section and on the maximum channel width, vary from 2500 to 4700 for water and 100 to 600 for oil. Accordingly, the water flow was simulated as turbulent, while the oil one was regarded as 
laminar. For the turbulent flow, two alternative turbulence models were used: the twoequation k- $\varepsilon$ one [9] and the one-equation Spalart-Allmaras one [10], without any major difference on the results. The results presented here correspond to the k- $\varepsilon$ model.

\section{VISUALIZATION RESULTS}

\subsection{Water flow}

When water is circulating, the flow pattern is similar for the two volumetric flow rates analyzed. When the dye is injected at the left side of the entrance orifice, it is observed that most of the liquid moves to the left, surrounding the blocked orifice, and travels downstream preferentially following the left channel, without moving along the corrugations. These streamlines extend until the lower part of the plate, where they bend again surrounding the blocked lower left orifice to end finally in the outlet orifice. In a similar way, for injection points on the right side of the entrance, the streamlines connect with the exit flowing in parallel to the right edge of the plate, without penetrating the central region. Only when the dye is injected from the central vertical diameter of the inlet, the fluid is observed to sometimes move along the grooves. From these injection points the streamlines open in an eye shape, covering most of the central part of the plate. Figure 5 a) shows the superposition of three images with left, center and right dye injection points for a water flow rate of $1.3 \mathrm{l} / \mathrm{min}$. The eddies clearly visible in both the inlet and outlet orifices are indicative of the turbulent nature of the flow. A similar superposition of three images is depicted in Fig. 5 b) for a flow rate of 2.0 1/min. Here, the flow pattern is very similar to the preceding case, but the died water mixes more rapidly due to its higher speed, covering the whole plate area. Figure 6 shows a detail of an instantaneous image to stress the presence of eddies in the inlet region.

\subsection{Water-glycerin mixture flow}

For the water-glycerin mixture, the flow pattern is similar, but the more viscous fluid mixes worse because the flow is essentially laminar, and the streamlines are more clearly 
visible. Figures 7 a) to $7 \mathrm{~d}$ ) are composite images displaying the 0.5, 1.0, 2.0 and $3.0 \mathrm{l} / \mathrm{min}$ flow rate cases. The dye injection points in each one are clearly identifiable. Again, the corrugations are not decisive in guiding the flow, and those fluid elements entering from the sides of the inlet orifice move preferentially to the sides of the plate. Occasionally, some died lines can be observed to follow the plate grooves, reflected in diagonal lines in the images. This behavior is more frequent for higher velocities. As could be expected, for increasing velocities and hence, increasing Reynolds numbers, the mixing improves and some small eddy structures can be observed especially at the exit. As opposed to the water case, vortices cannot be distinguished in the entrance orifice.

\section{VELOCIMETRY RESULTS}

Velocity measurements have been obtained for the central region of the plate. As previously stated, the image field of view has been $3.2 \times 3.2 \mathrm{~cm}$, so that two images have been required to cover the whole plate width, $6 \mathrm{~cm}$, with a $0.2 \mathrm{~cm}$ overlap between them. Table 1 presents average velocity values for the right and the left images for all the flow conditions studied. It can be seen that the average longitudinal velocity is slightly higher on the right side of the plate, due to the non-symmetrical location of the plate inlet and outlet that are also displaced to the right. This difference is more noticeable for the more viscous fluid, for which the flow is less homogeneous. The horizontal velocity component is substantially lower than the vertical one. This result is in good agreement with the visualization images. The flow tends to move preferentially downwards, with relatively little influence of the diagonal grooves. Furthermore, in some cases, the streamlines present a zigzag shape, so it is logical that the average transverse velocity is close to zero.

Figure 8 shows some instantaneous velocity maps for a flow rate of $1.31 / \mathrm{min}$ of water, while Figure 9 depicts the corresponding ones to a water flow rate of $2.0 \mathrm{l} / \mathrm{min}$. In all the processed images, bad vectors have been discarded, but neither smoothing nor interpolation has been applied. Some windows without any valid velocity vector correspond to the contact points between the upper and lower plates, as reflected in Fig. 4. For both water flow rates, the lateral channels at the plate edges are clearly visible. In the 
upper right corner of the left area maps, the velocity vectors tend to deviate towards the left, due to the expansion after the entrance through the inlet orifice that would be located above the area covered by the right side images. Similarly, in the lower part of the left area images, the velocity vectors are displaced towards the right, as they direct to the outlet orifice. For the same reason, vectors in the lower right part of Figs. 8 and 9 are slightly oriented towards the left. In the central region, velocity values are lower, with the streamlines following a certain zigzag patterns.

Two velocity maps for the water/glycerin mixture are shown in Figures 10 and 11 for $0.5 \mathrm{l} / \mathrm{min}$ flow rate, and $3 \mathrm{l} / \mathrm{min}$ condition, respectively. Again, the flow structure is analogous to that obtained for the water cases. The preferential displacement along the side channels is apparent, with some sinuous movement in the central part. Again, streamlines are curved to the left in the upper right corner, and to the right in the lower part, approaching the outlet.

\section{NUMERICAL RESULTS}

The simulation results are largely in line with the experimental findings. Figure 12 a) presents the water flow pattern as indicated by the streamlines arising from the inlet orifice, for the case with a flow rate of $1.67 \mathrm{l} / \mathrm{min}$. This can be compared with the corresponding visualization images for a similar flow in Fig. 5. Once a provision is made for the effect of diffusion of the dye in the experimental setup for this turbulent flow, several common features that can be seen in the flow structure as revealed by the experimental approach are also present in the computational one. Thus, the flow can be seen as being preferentially longitudinal, and only occasionally following the direction of the grooves. One of these occasions is the expansion of the inlet flow to fill the central region of the plate (marked A in Fig. 13), where the flow moves along the grooves; Fig. 5

a) corroborates experimentally the existence of such a pattern for the water flow. Another clear similarity is the existence of a stream, marked B in figure 12, which arises at the back of the inlet orifice and moves around the blocked orifice along the periphery of the device. At the exit orifice, C, a large-scale eddy is induced by the curved boundary of the plate. 
Typical calculated results for oil are shown in Fig. 12 b), for a flow rate of 0.91 1/min. These can be compared with the visualization results of figure $7 \mathrm{~b}$ ), for a flow rate of $1 \mathrm{l} / \mathrm{min}$. As for the experimental work, the calculated average flow patterns from oil and water do not differ significantly, the main qualitative difference being the absence of the exit eddy.

Figure 13 shows the mass flow rate per unit area on the central cross-section of the exchanger for the water and for oil. The calculations indicate that the flow distribution for oil is more uniform than it is for water, for which the peripheral streams turn out to have a higher velocity. However, the mass flow rate distribution when water is circulating is more symmetrical with respect to the plate longitudinal axis, while for oil it is visibly displaced to the side where the inlet and outlet orifices are located. This fact is in good agreement with the measurements presented in Table 1, where a higher left-right asymmetry is evidenced for the water/glycerin mixture, which increases as the flow rate rises.

\section{CONCLUSIONS}

An experimental study has been performed to analyze the flow between two plates of an oil/water heat exchanger designed for the automotive industry. In the experiments, the oil has been replaced by a water/glycerin mixture with the same kinematic viscosity. The flow structure has been studied using PLIF visualization and PIV velocity measurements with fluorescent particle tracers, and has been simulated with a CFD code. With both fluids, water and water/glycerin, and for all the flow rates tested, the streamlines follow similar patterns. The flow moves preferentially and with higher velocities along the lateral channels, at the sides of the plate. The plate has $\mathrm{V}$-shaped grooves in a herringbone configuration that should force the fluid in a zigzag path. However, this purpose is only partially fulfilled. For water, the mixing is higher and fluid elements entering from any point of the inlet can circulate along the grooves, although again, those streamlines starting from the inlet edges tend to occupy the lateral channels. In the case of the water/glycerin mixture, this behavior is more pronounced. Only the fluid elements entering from the central part of the inlet move through the central part of the plate, poorly following the 
corrugations. In this sense, it can be concluded that the objective of maximizing the residence time and the heat exchange surface has not been successfully achieved, and the plate design can be optimized. A first modification that should improve the flow would be to extend the corrugations a bit more into the lateral channels, thus reducing their width.

It has also been demonstrated that the numerical simulations reflect with high accuracy all the flow features observed experimentally. Hence, CFD can be used as a powerful predictive tool to improve the plate design.

\section{ACKNOWLEDGEMENTS}

This work has been supported by Valeo Engine Cooling.

\section{REFERENCES}

[1] Seligman, R. J. S. (1964), The plate heat exchanger in the food industries - Part I: Genesis of an idea, Chemistry and Industry, 38, 1602-1603

[2] Reppich, M. (1999), Use of high performance plate heat exchangers in chemical and process industries, Int. J. Thermal Sciences, 38, 999-1008

[3] Würfel, N. and Ostrowski, R., (2004), Experimental investigations of heat transfer and pressure drop during the condensation process within plate heat exchangers of the herringbone-type. Int. J. Thermal Sciences, 43, 59-68

[4] Miyara, A., Otsubo, Y, (2002), Condensation heat transfer of herringbone micro fin tubes, Int. J. Thermal Sciences, 41, 639-645

[5] Ribeiro, C.P. and Caño Andrade, M.H., (2002), An algorithm for steady-state simulation of plate heat exchangers, J. Food Eng., 53, 59-66

[6] Gut, J.A.W. and Pinto, J.A., (2003), Modeling of plate heat exchangers with generalized configurations, Int. J. Heat and Mass Transfer, 46, 2571-2585

[7] Wang, Z.Z., Zhao, Z.N., (1993), Analysis of performance of steam condensation heat transfer and pressure drop in plate condensers, Heat Transfer Eng., 14 (4) 32-41

[8] Brackmann, U., (1994), Lambdachrome Laser Dyes, p. 160-161, Lambda Physik GmbH, Göttingen, Germany, 1994. 
[9] Jones, W.P., Launder, B.E., (1972), The prediction of relaminarization with a twoequation model of turbulence, Int. J. Heat Mass Transfer, 15, 301-314

[10] Spalart, P.R., Allmaras, S.R., (1994), A one-equation turbulence model for aerodynamic flows, La Recherche Aérospatiale, 1, 5-21 


\section{Figure Captions}

Fig. 1: Heat exchanger studied: a) one of the aluminum plates that forms the stack in the final assembly, b) sketch of the stacking procedure.

Fig. 2: Experimental assembly using a black-painted original plate and a mechanized and polished metacrylate cover piece.

Fig. 3: Optical arrangement used for both visualization and PIV experiments.

Fig. 4: Detail of the computational mesh.

Fig. 5: Experimental flow visualization showing the superposition of three images with left, center and right dye injection points for two constant water flows: a) 1.3 1/min., b) 2 1/min.

Fig. 6: Close-up of the inlet region showing the presence of small eddies. Flow conditions correspond to a water flow rate of $2.0 \mathrm{l} / \mathrm{min}$.

Fig. 7: Set of images for the water/glycerin mixture corresponding to flow rates of a) 0.5 1/min, b) $1.0 \mathrm{l} / \mathrm{min}$, c) $2.0 \mathrm{l} / \mathrm{min}$ d) $3.0 \mathrm{l} / \mathrm{min}$. Injection points are clearly discernible.

Fig. 8: Velocity map for water flowing at $1.31 / \mathrm{min}$.

Fig. 9: Velocity map for water flowing at $2.01 / \mathrm{min}$.

Fig. 10: Velocity map for water/glycerin mixture at a flow rate of $0.51 / \mathrm{min}$.

Fig. 11: Velocity map for water/glycerin mixture corresponding to a flow rate of $3.0 \mathrm{l} / \mathrm{min}$.

Fig. 12: Streamlines for a) water (flow rate: $1.671 / \mathrm{min}$ ) and b) oil (flow rate; 0.91 1/min).

Fig. 13: Computed mass flow rate per unit area on the exchanger cross-section for water (top, flow rate: $1.67 \mathrm{l} / \mathrm{min}$ ) and for oil (bottom, flow rate; $0.91 \mathrm{l} / \mathrm{min}$ ). 


\begin{tabular}{|c|c|c|c|c|c|}
\hline Fluid & $\begin{array}{c}\text { Flow rate } \\
(1 / \text { min) }\end{array}$ & \multicolumn{2}{|c|}{ Left area } & \multicolumn{2}{c|}{ Right area } \\
\hline \multirow{3}{*}{ Water } & 1.3 & 0.004 & 0.21 & 0.03 & 0.30 \\
\cline { 2 - 6 } & 2.0 & -0.007 & 0.39 & -0.003 & 0.61 \\
\hline \multirow{3}{*}{$\begin{array}{c}\text { Water } \\
+ \\
\text { glycerin }\end{array}$} & 0.5 & -0.002 & 0.095 & 0.017 & 0.10 \\
\cline { 2 - 6 } & 1.0 & -0.004 & 0.16 & 0.027 & 0.42 \\
\cline { 2 - 6 } & 2.0 & -0.009 & 0.28 & 0.083 & 0.69 \\
\hline
\end{tabular}

Table 1: Average velocity values for the right and left images for the different experimental conditions studied. 


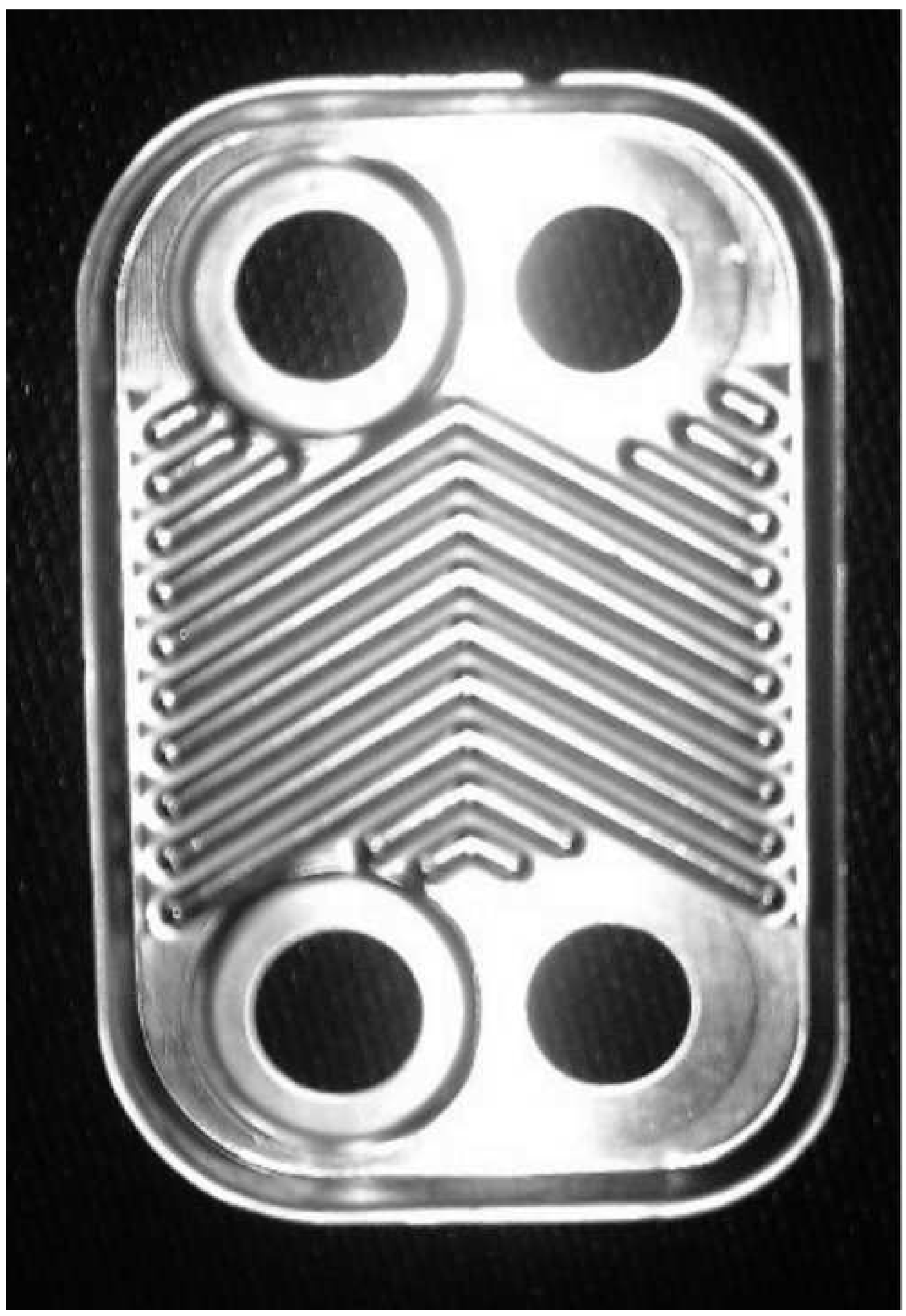




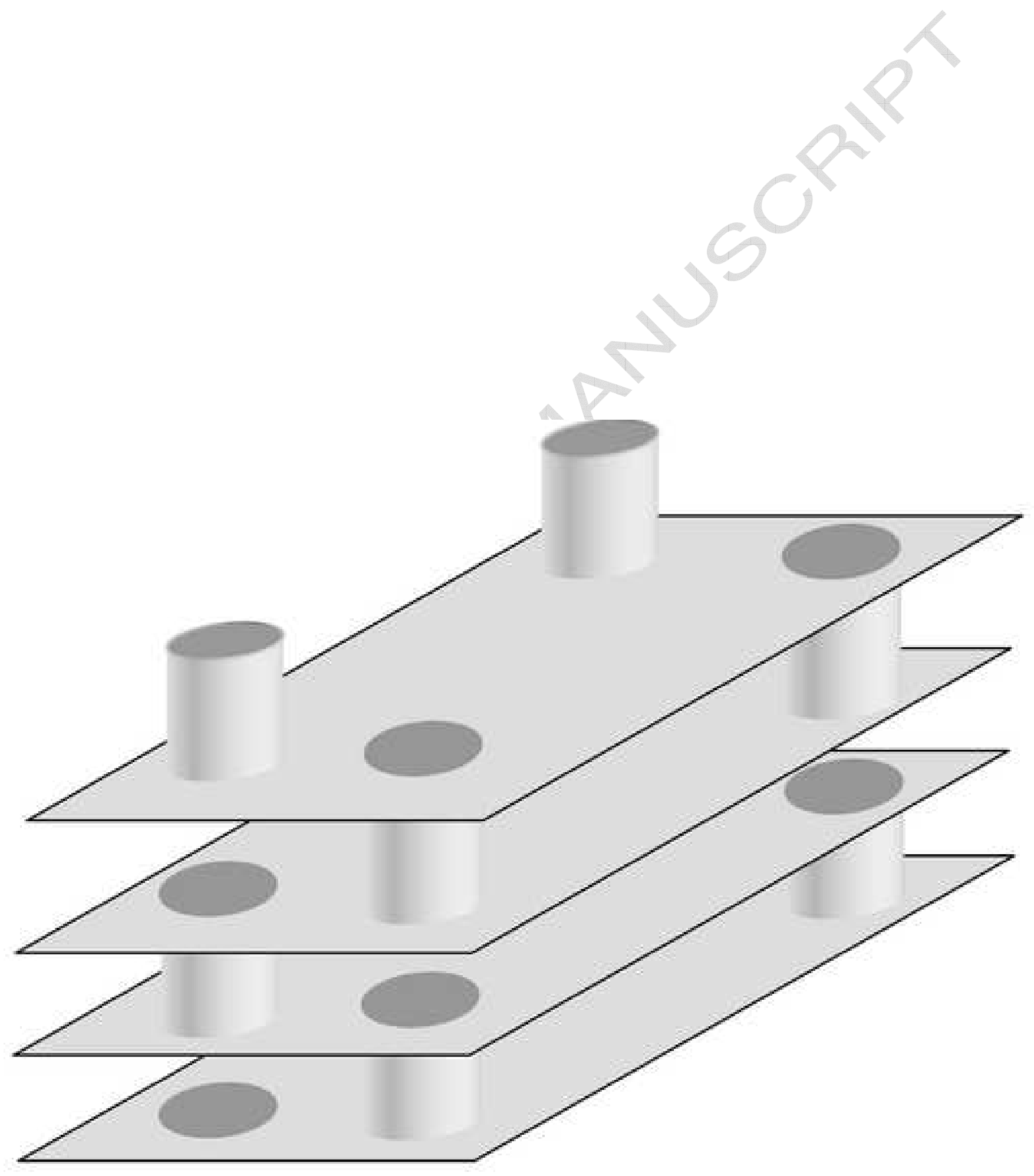




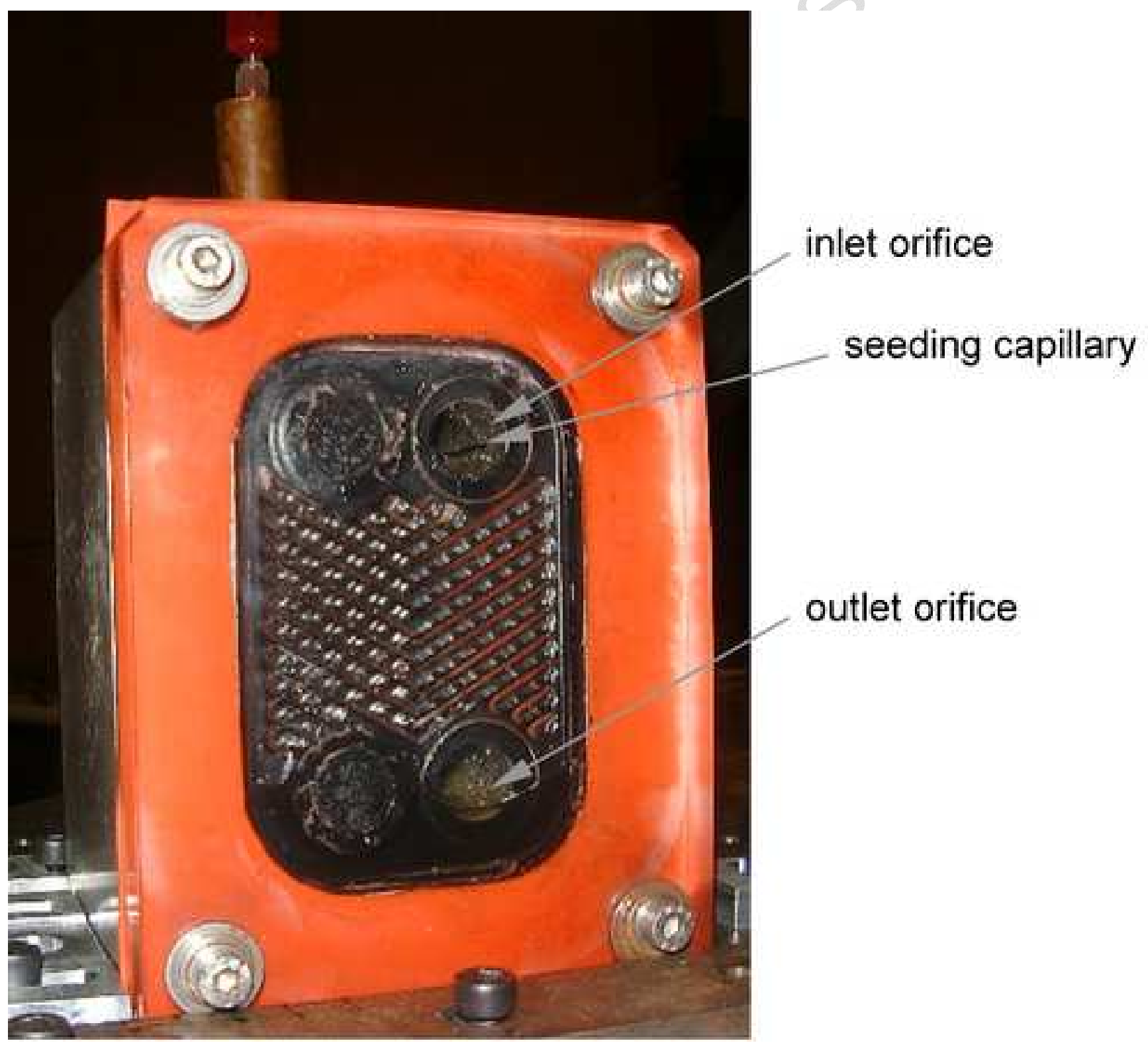




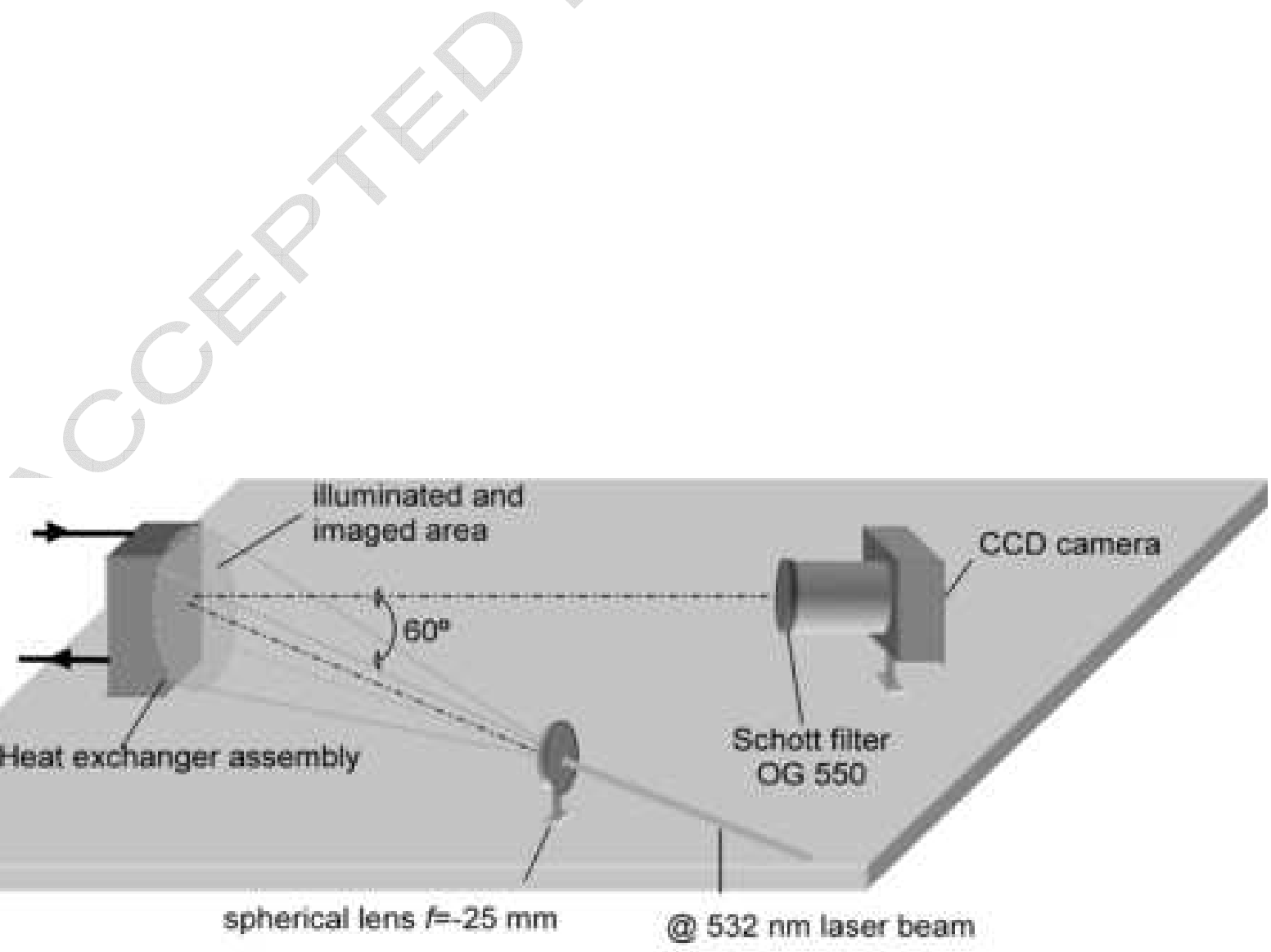




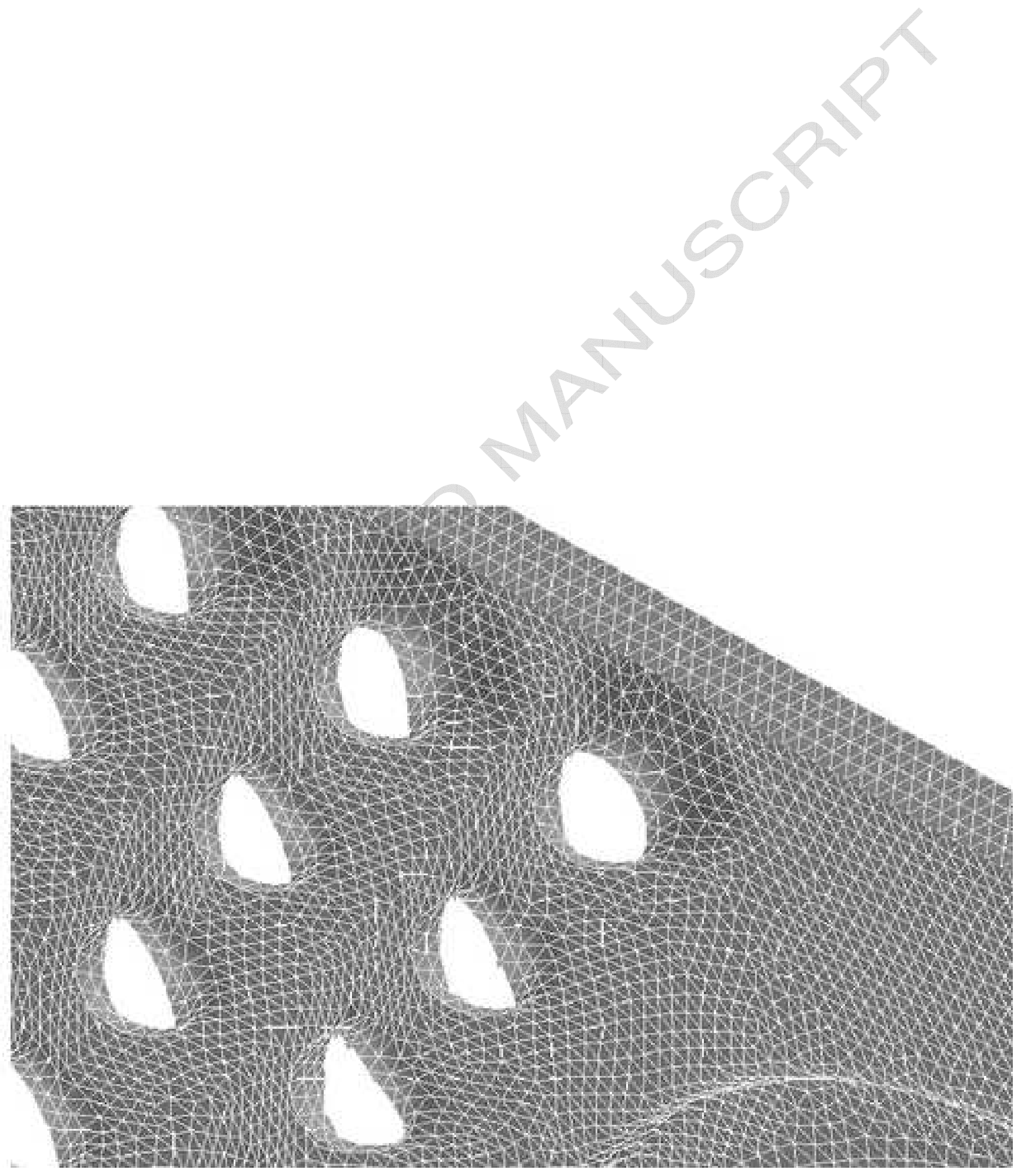


ACCEPTED MANUSCRIPT

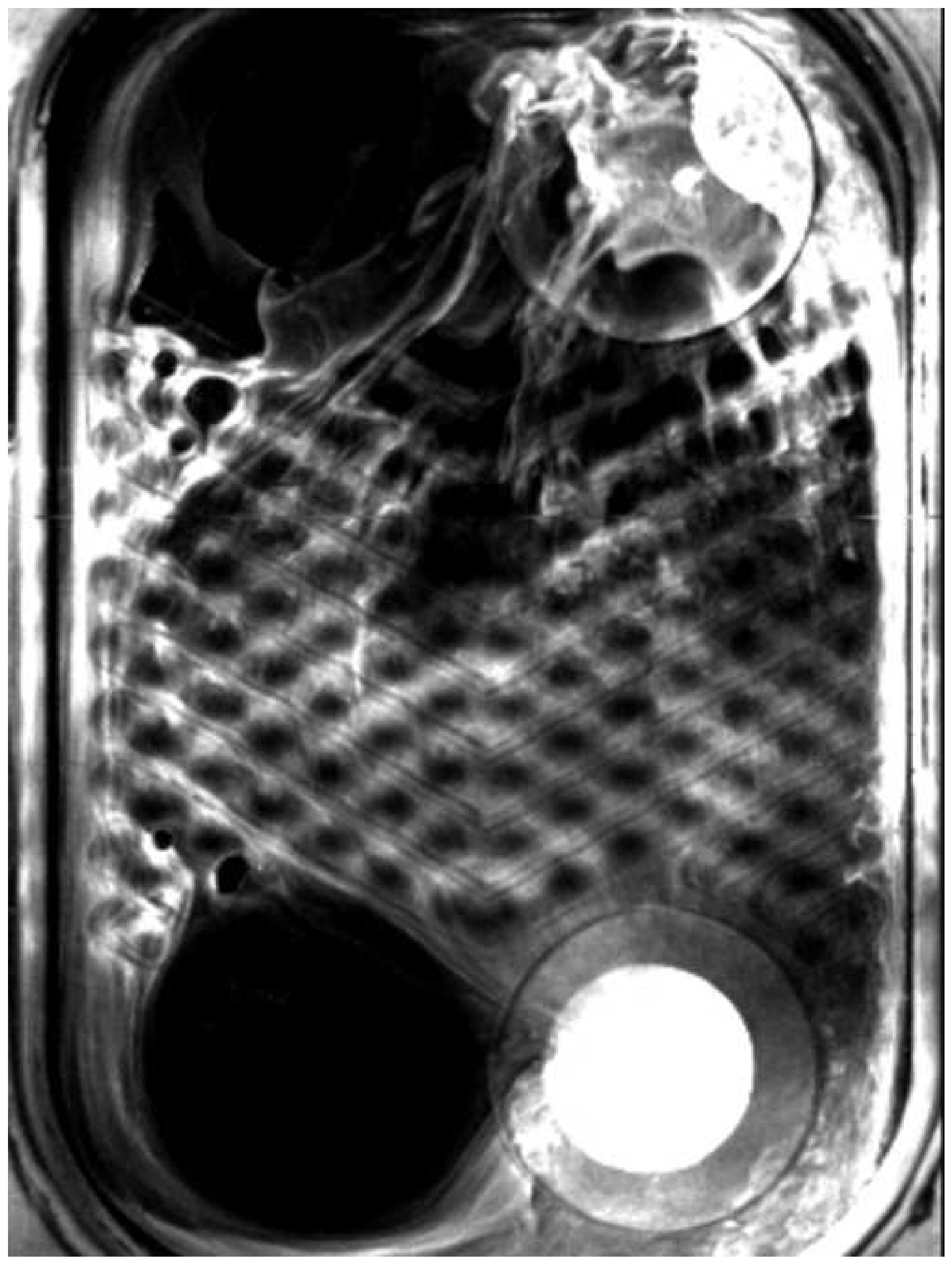


ACCEPTED MANUSCRIPT

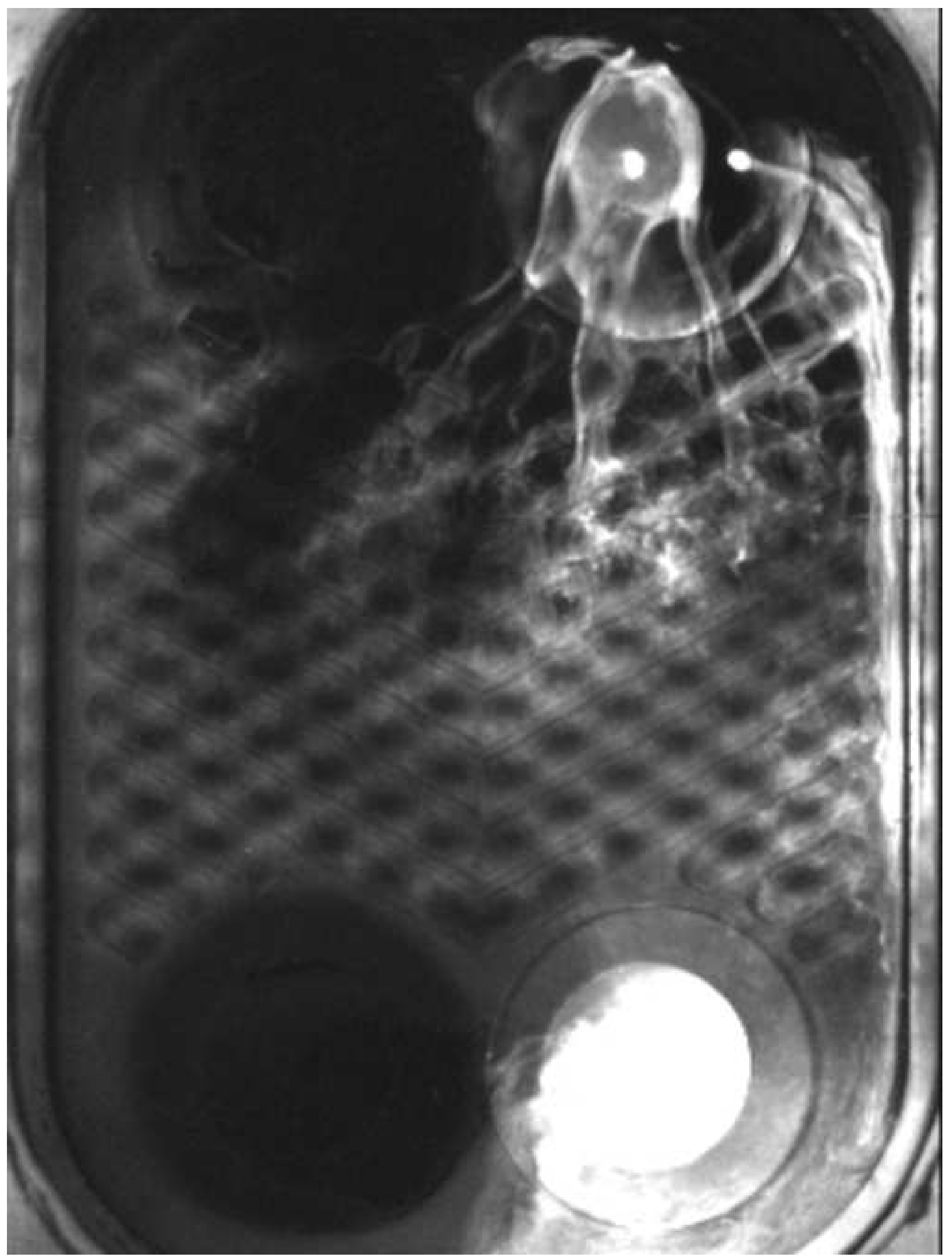




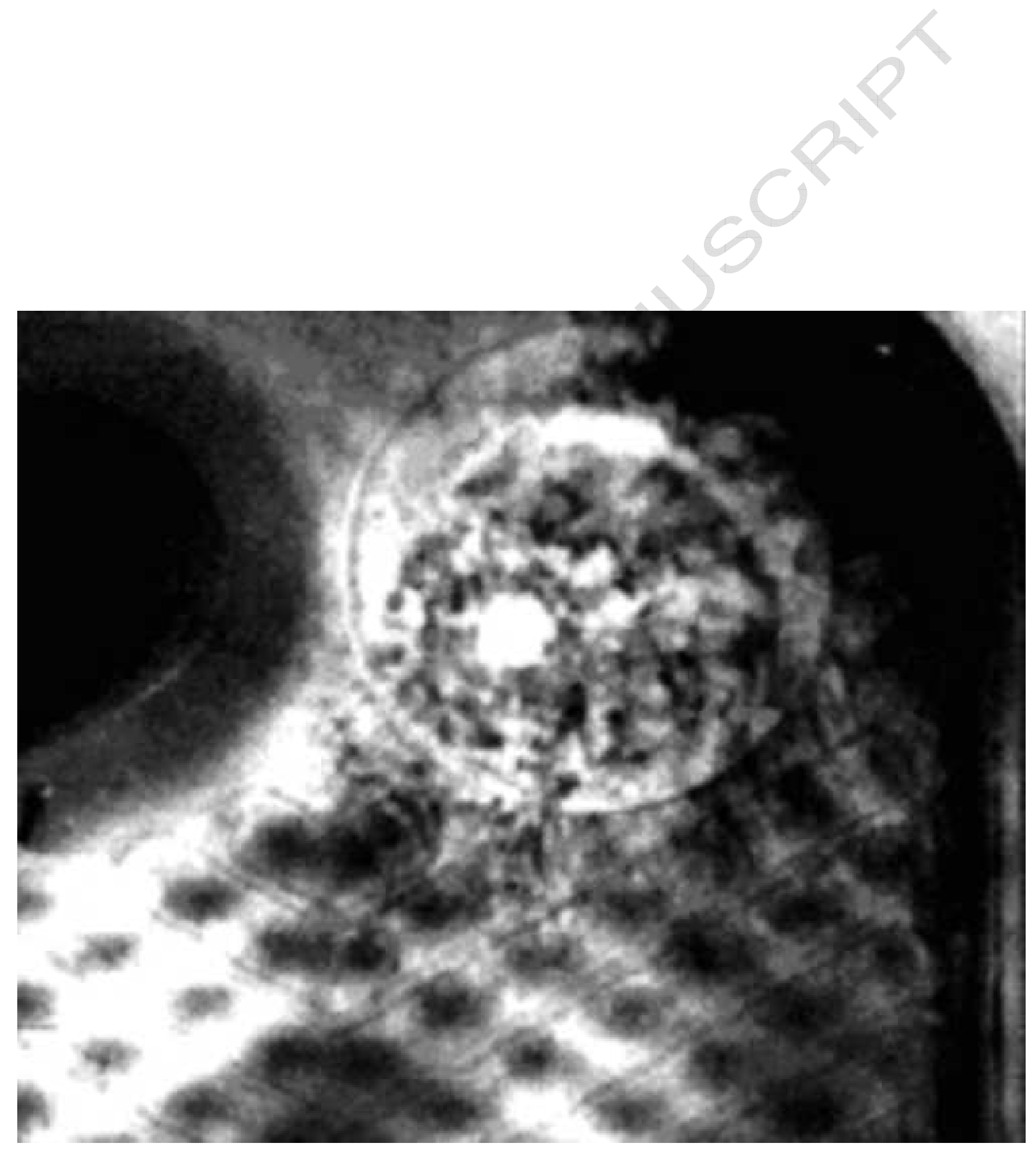


ACCEPTED MANUSCRIPT

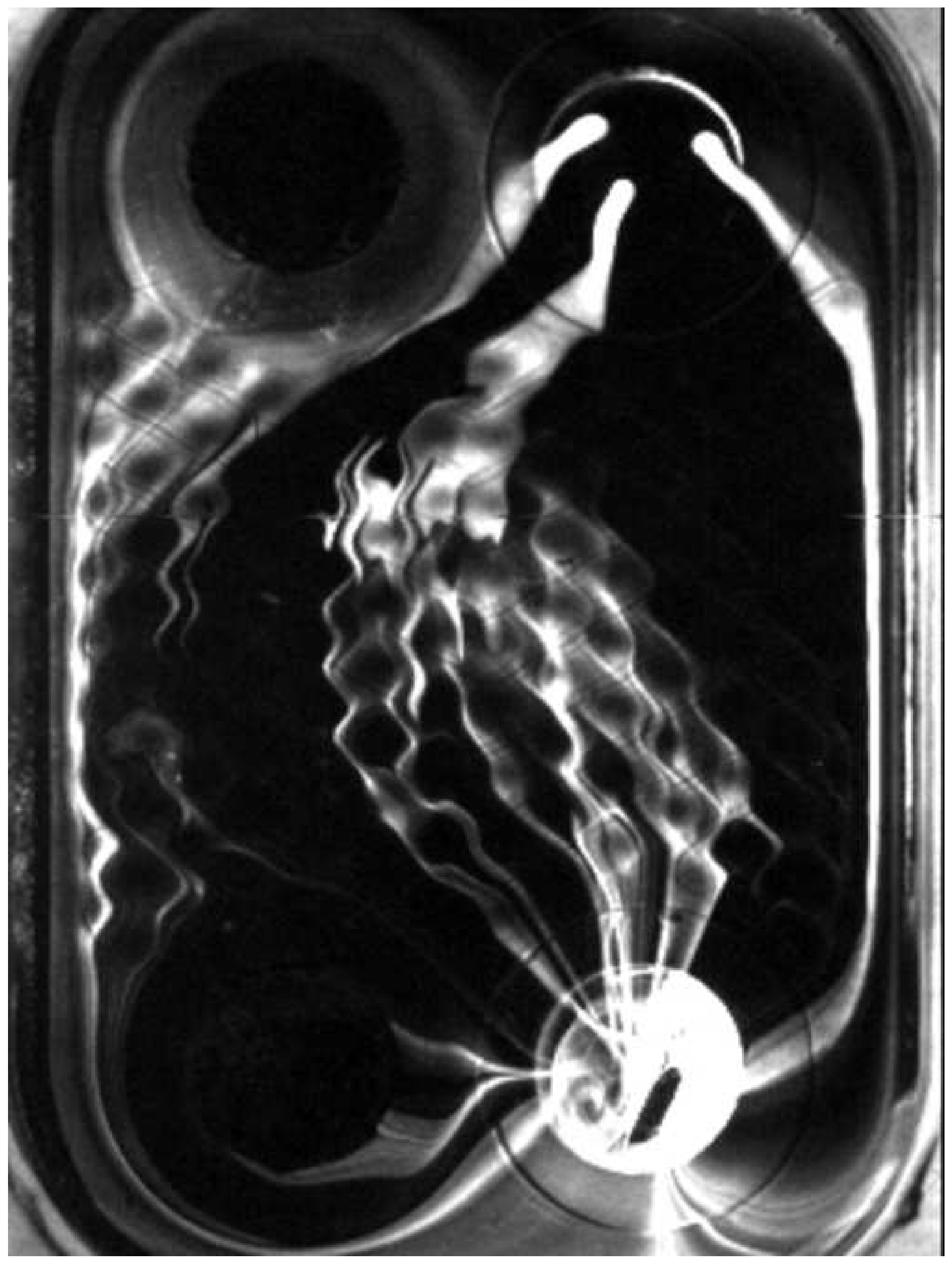


ACCEPTED MANUSCRIPT

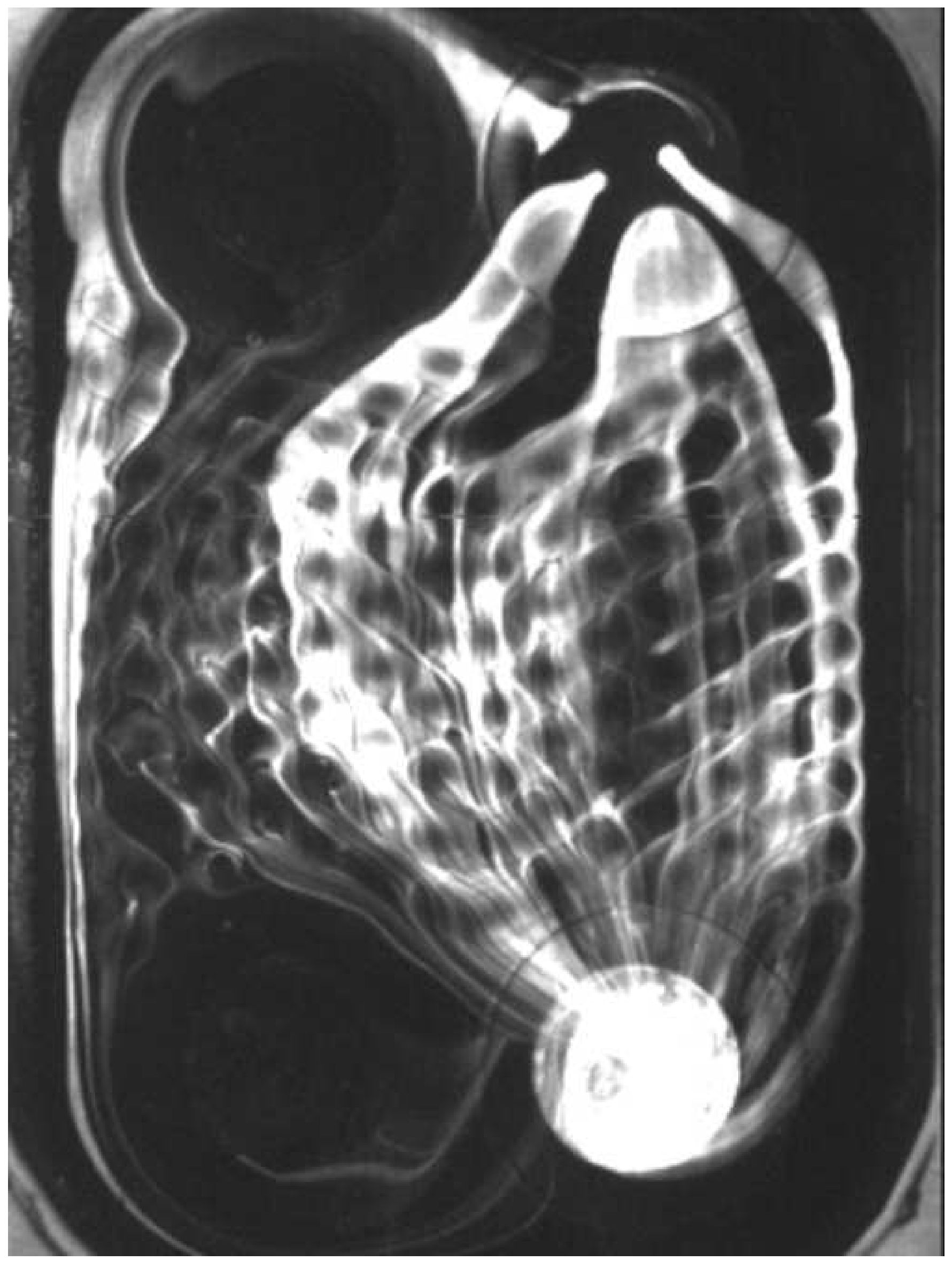


ACCEPTED MANUSCRIPT

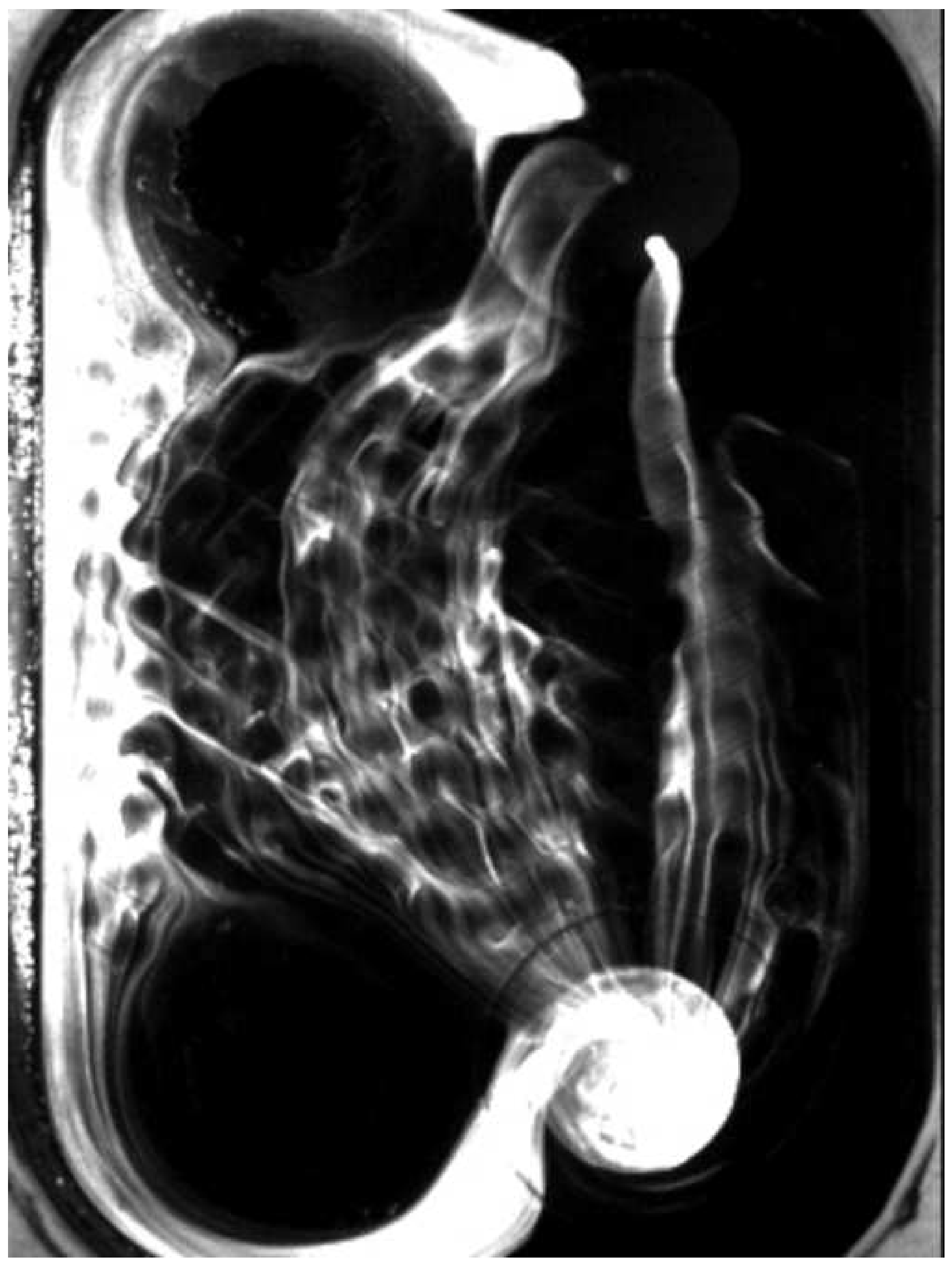


ACCEPTED MANUSCRIPT

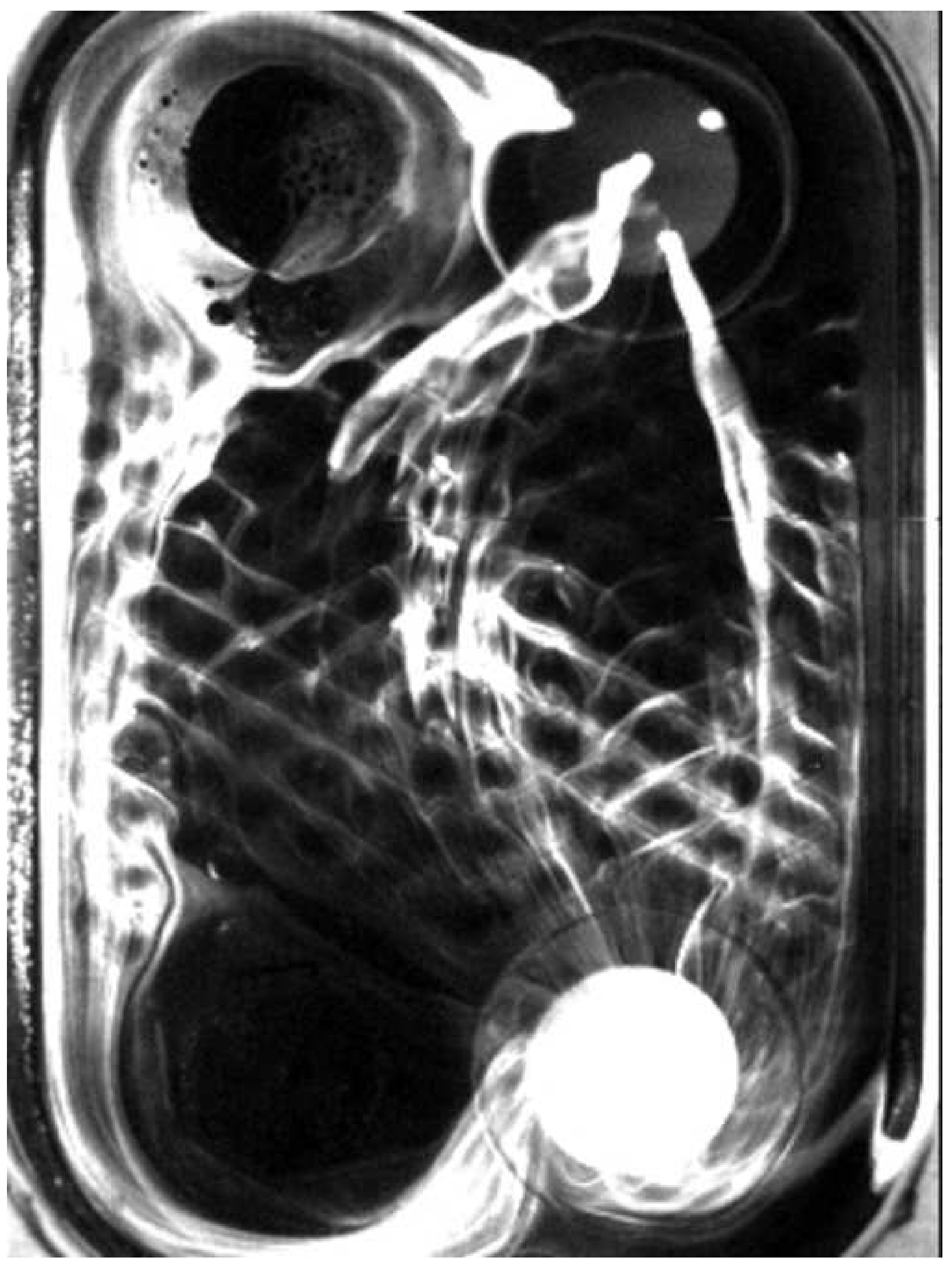




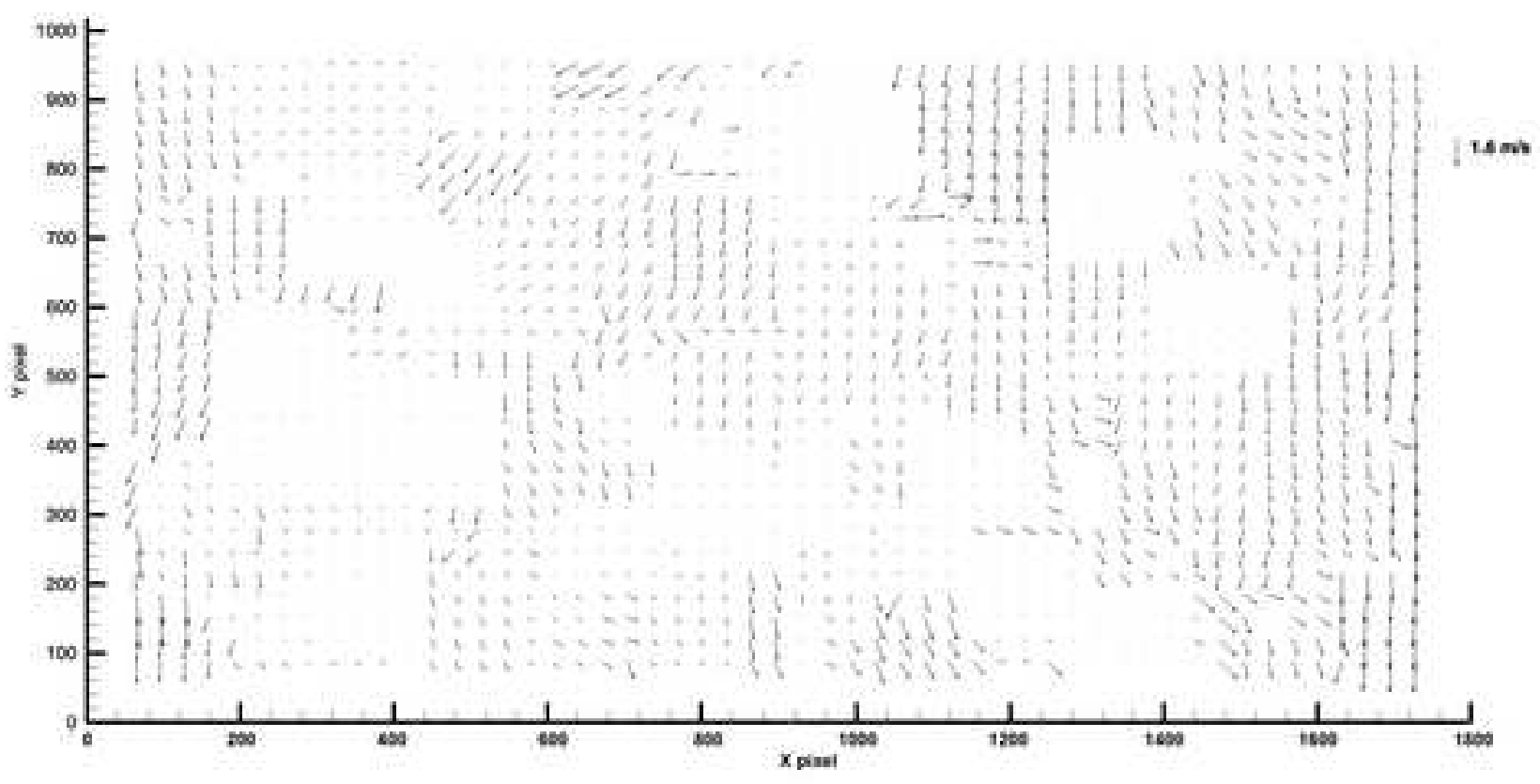




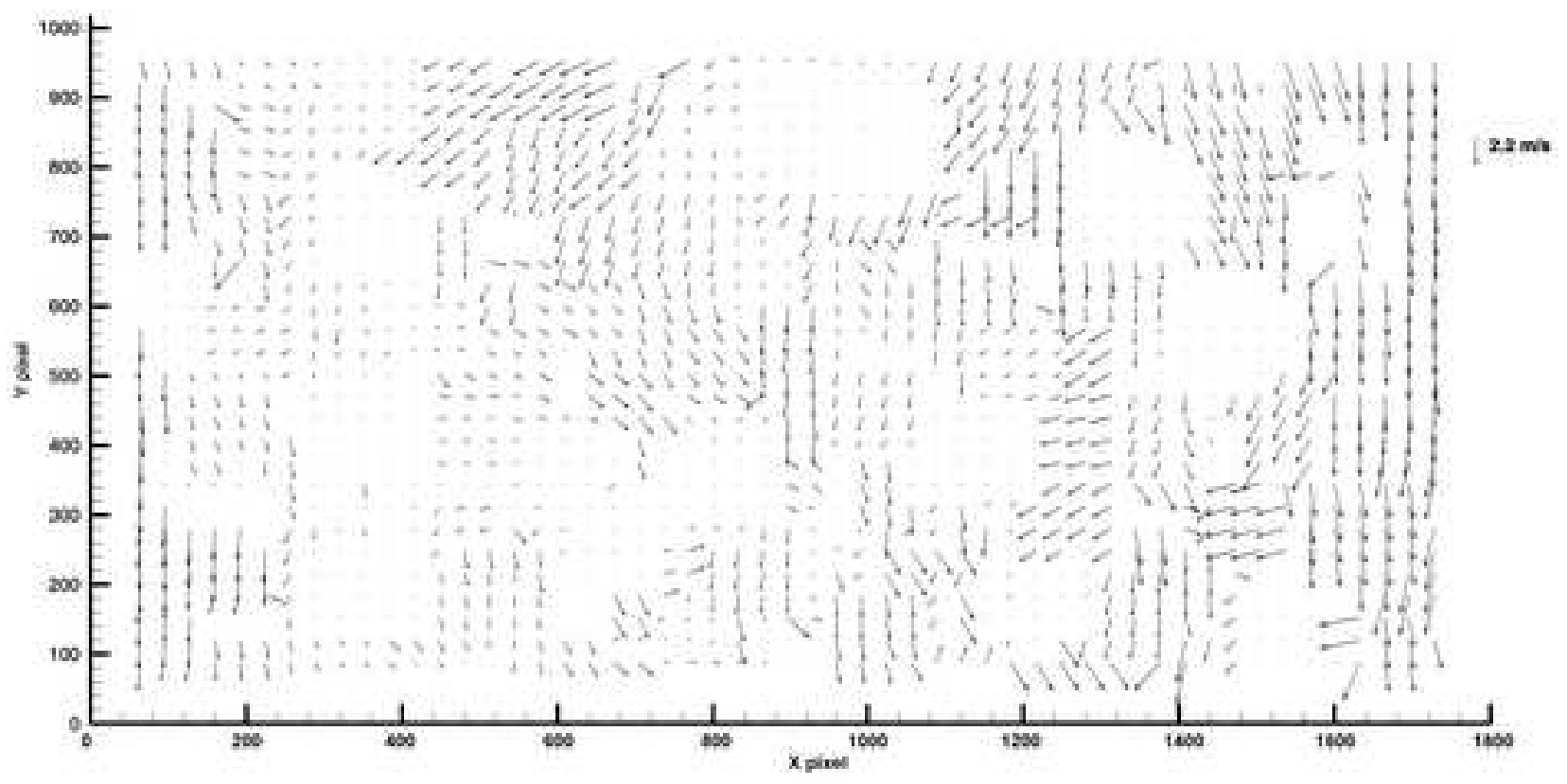




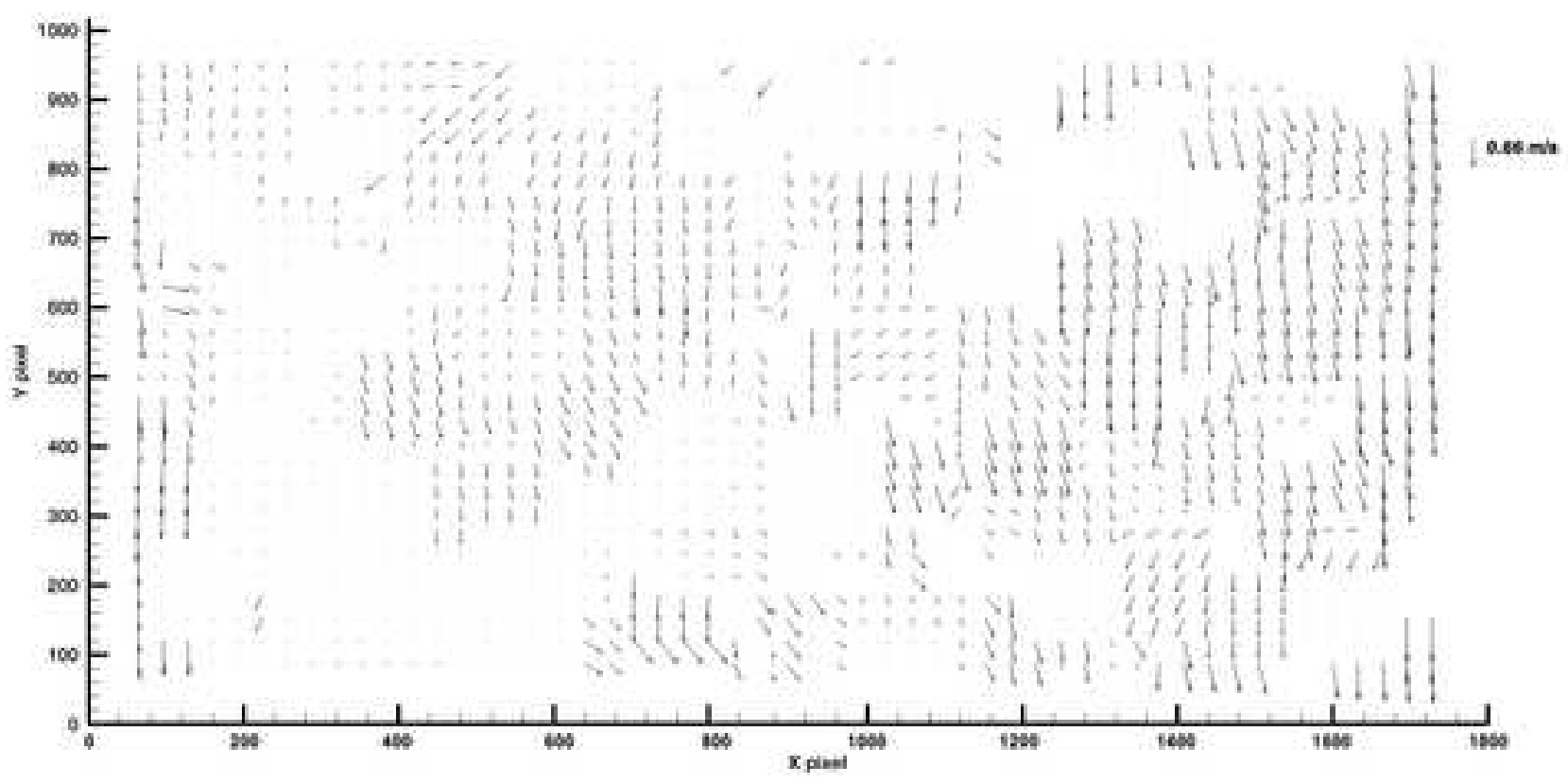




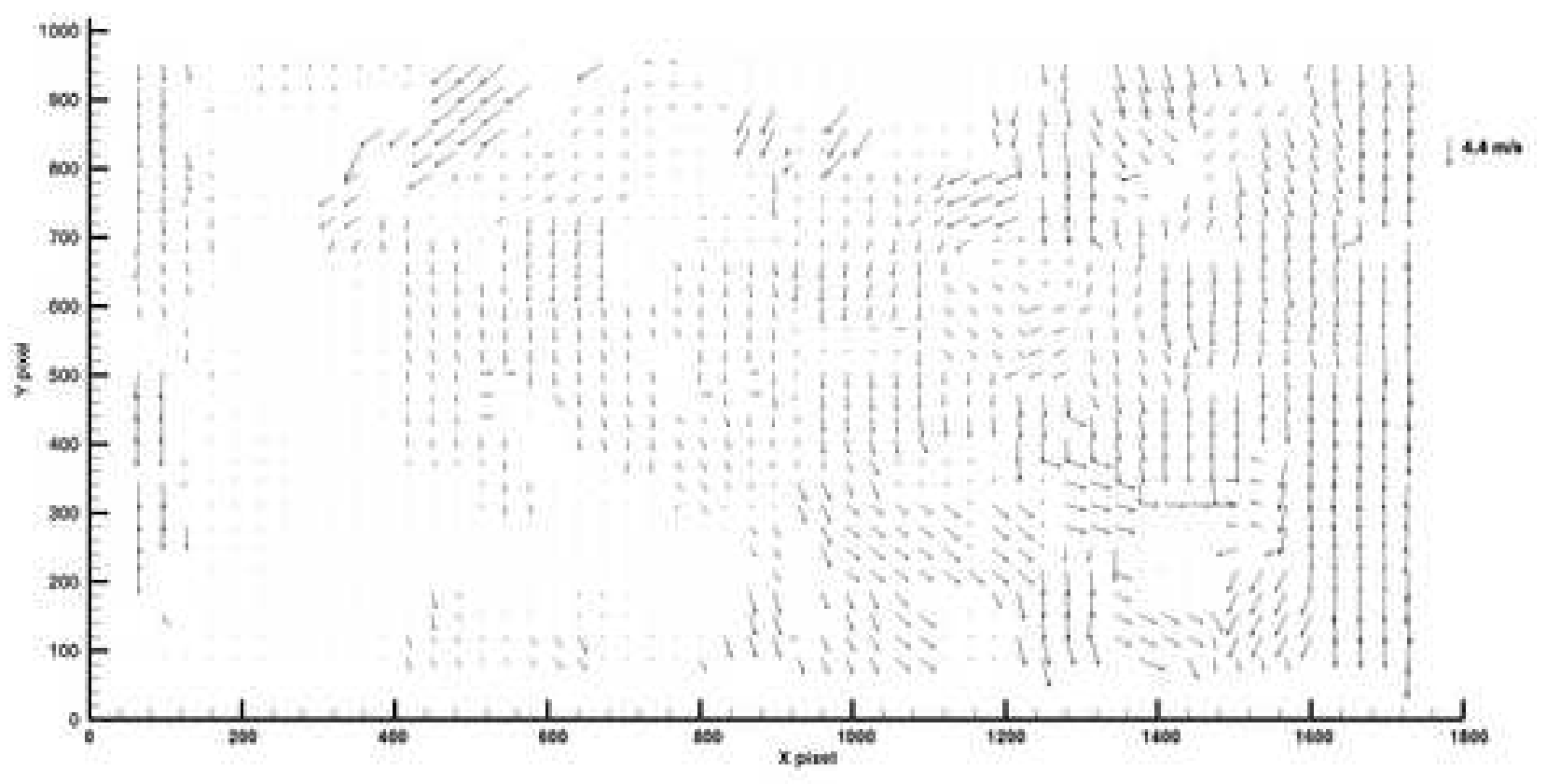




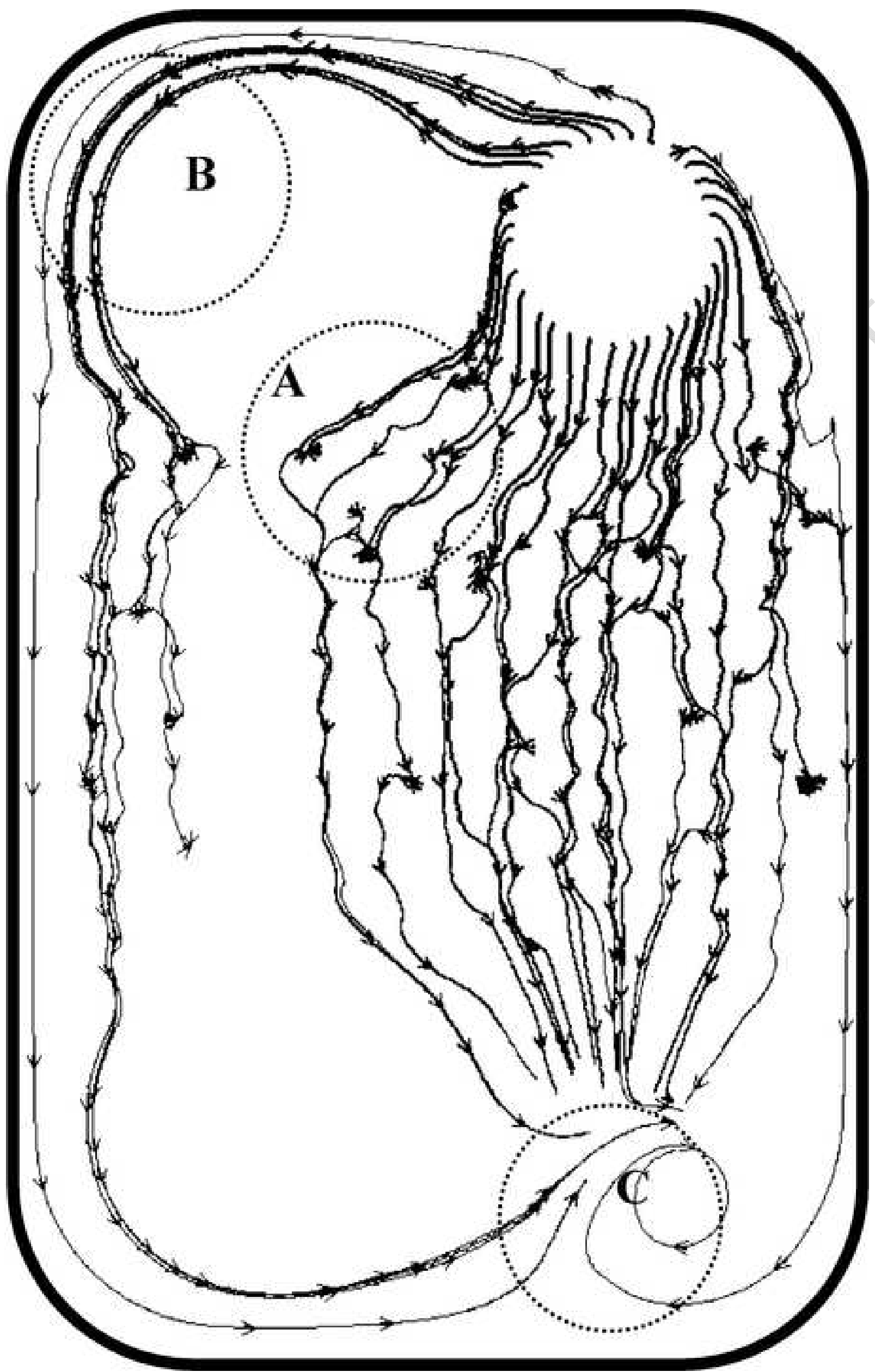




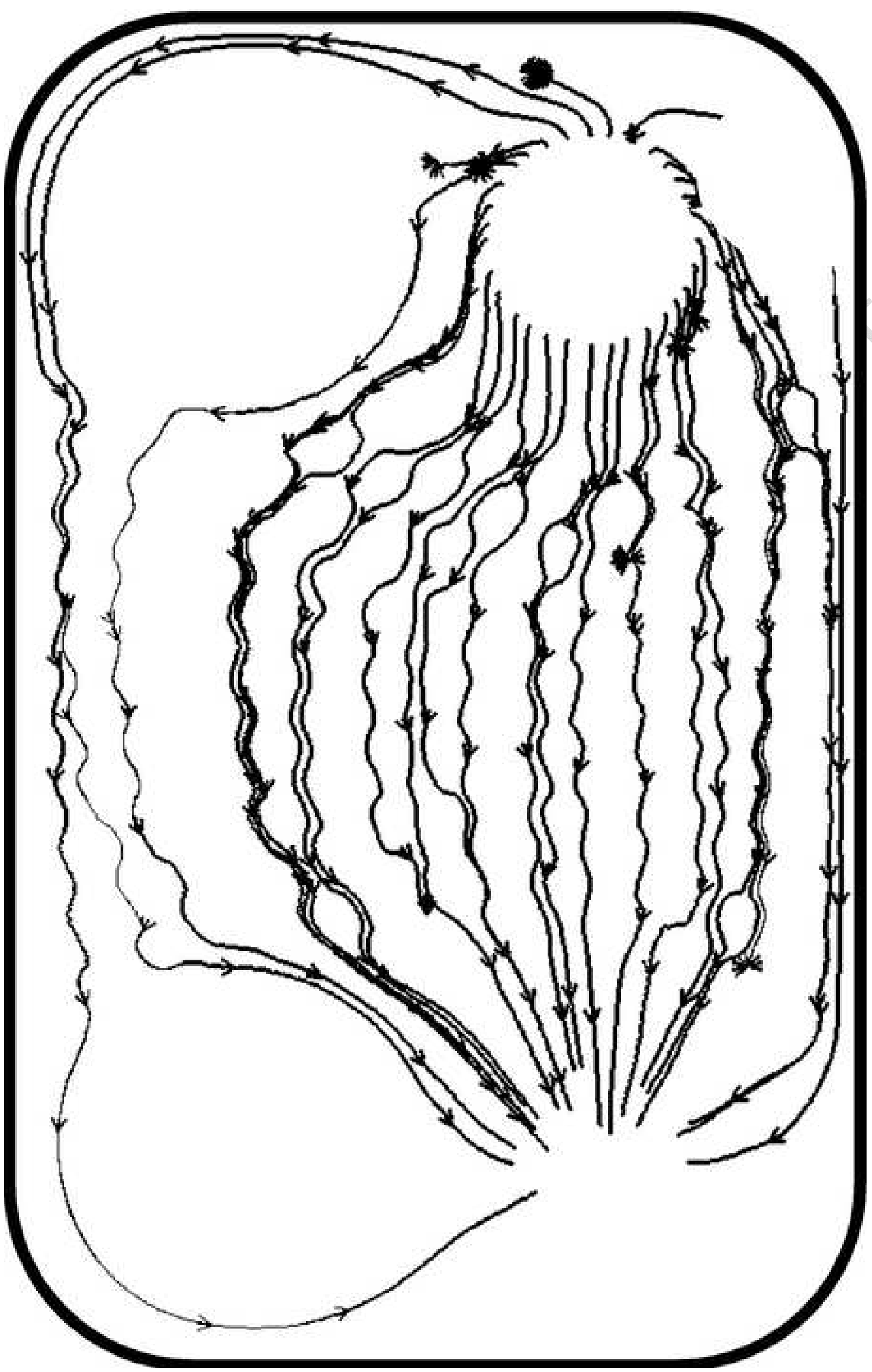




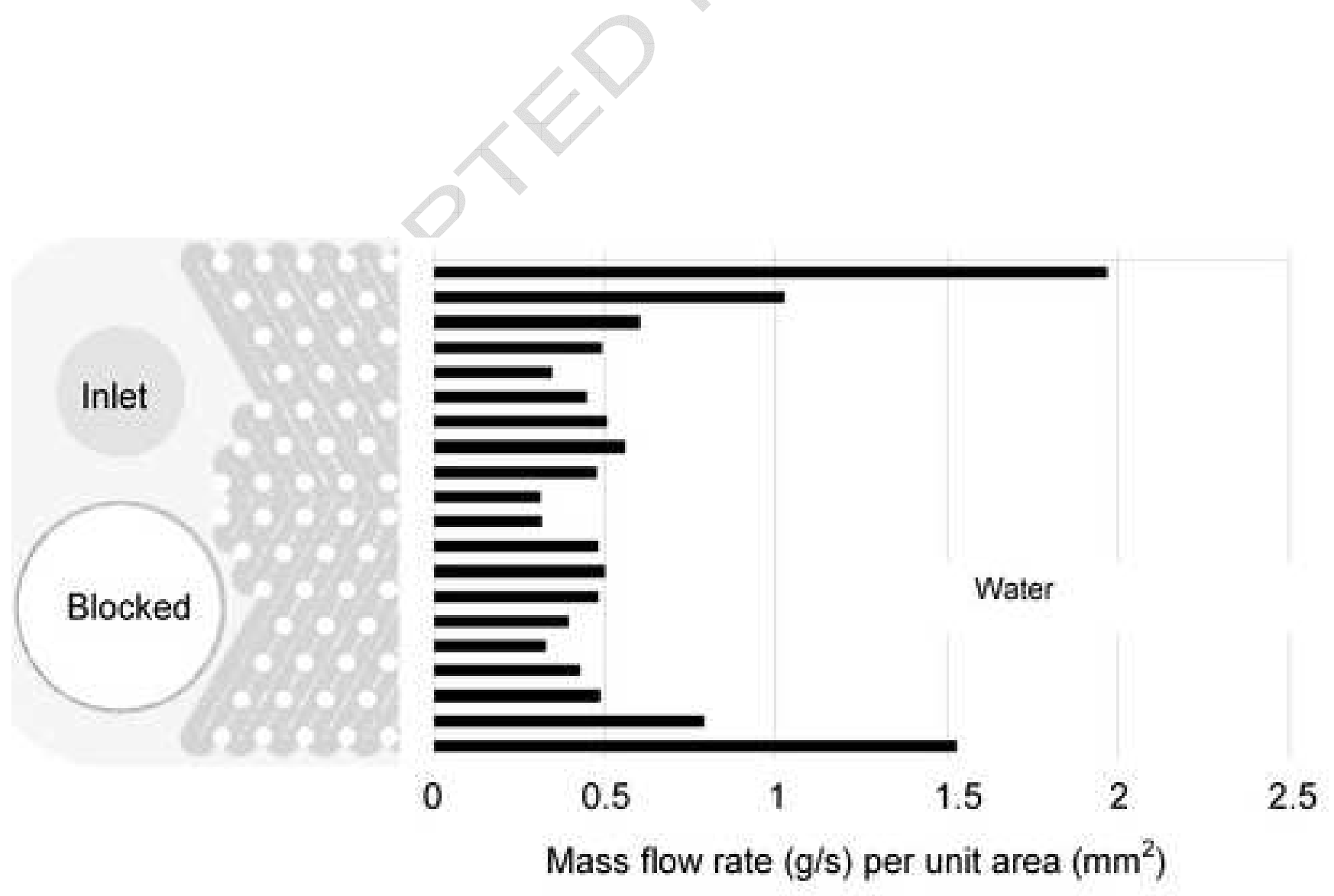




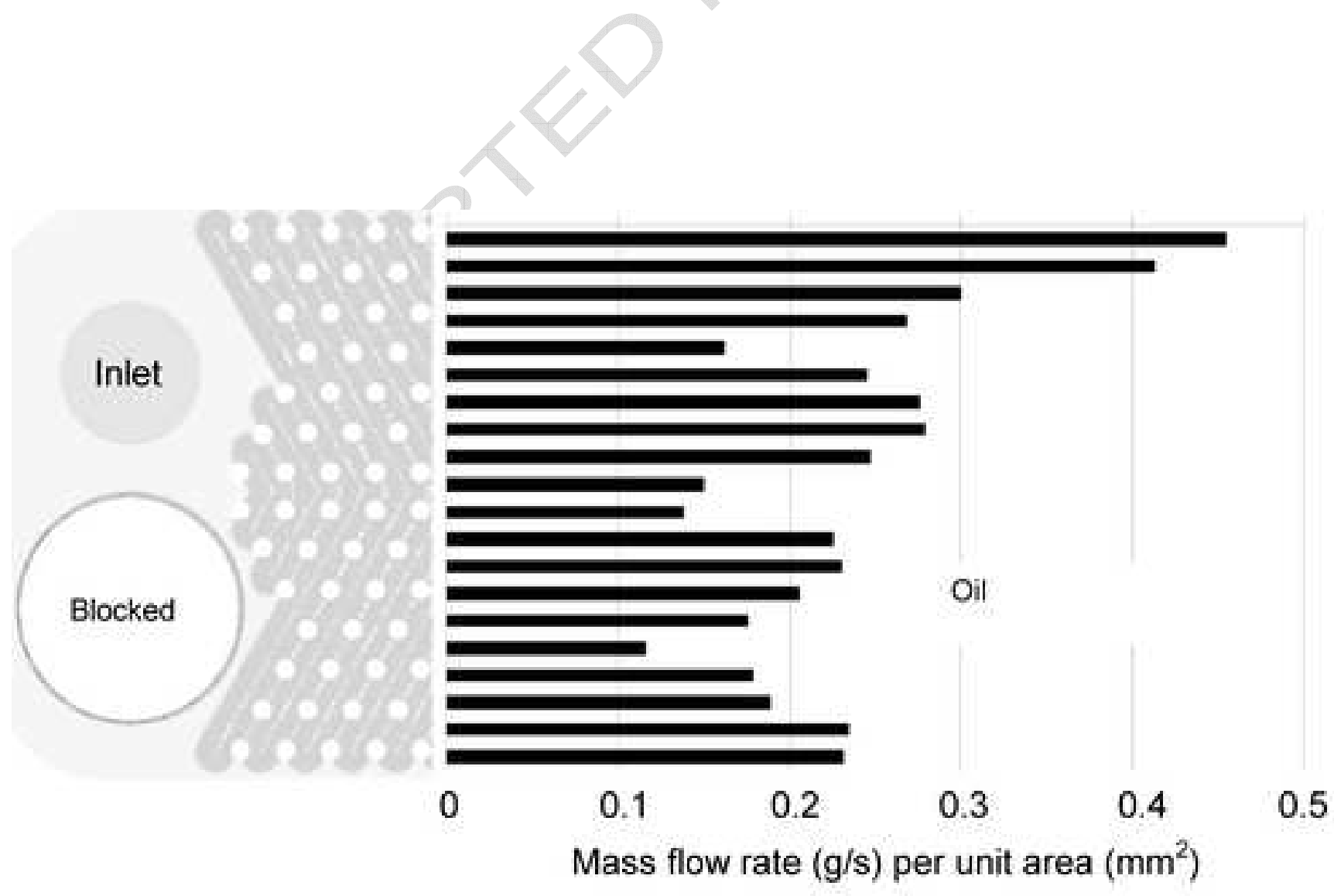

